\title{
El Significado de la Práctica de Disección para los Estudiantes de Medicina
}

\author{
What the Dissection Meaning for Medical Students \\ Beatriz Georgina Montemayor Flores
}

MONTEMAYOR, F. B. G. El significado de la práctica de disección para los estudiantes de Medicina. Int. J. Morphol., 24(4):575-580, 2006.

RESUMEN: El origen de la práctica de disección se remonta siglos atrás, en el tiempo del Museo de Alejandría (III a.C.). Durante casi 23 siglos esta práctica se ha transformado, desde un ejercicio racional hasta la simulación en la "realidad virtual" pasando por la prohibición y el dictado fiel a los cánones impuestos por los anatomistas galénicos.

¿Qué opinan sobre la disección los alumnos de medicina del siglo XXI quienes durante el primer año de su formación habrán que enfrentarse de manera cotidiana a esta actividad? Eso le preguntamos a los alumnos de primer año de la Facultad de Medicina de la Universidad Nacional Autónoma de México.

Los resultados de este trabajo nos hablan de la vigencia de esta antigua y moderna estrategia que permite acercarse a la realidad física y espacial del cuerpo humano.

PALABRAS CLAVE: Anatomía humana; Disección; Educación médica; Enseñanza de la anatomía.

\section{INTRODUCCIÓN}

La práctica de disección en Anatomía es con mucho uno de los recursos más antiguos en educación médica, la tradición escolar de la disección se remonta a la época de los Ptolomeos, en la Escuela de Alejandría, donde el estudio de la Anatomía fue fundada sobre la disección de cadáveres (Barquín, 1995).

Durante el reinado de Ptolomeo I, que duró casi 50 años, se establecieron tres instituciones que harían de Alejandría una ciudad tan importante como Roma en los siglos III a I a. C., las cuales le otorgaron un sitio privilegiado en la historia de la cultura occidental, El Faro, El Museo y La Biblioteca (Barquín).

La Casa de las Musas o Museo, construido y sostenido en su totalidad con fondos reales, funcionaba como un instituto de investigación humanística, artística y científica, abierto a los estudiosos de prestigio y a sus alumnos sin restricciones geográficas ni raciales. El Museo atrajo a literatos, filósofos, artistas y científicos, entre ellos a dos anatomistas; Herófilo de Calcedonia y Erasistrato de Chios (Montemayor, 1999).
Todas las grandes culturas han estudiado el cuerpo humano desde diferentes enfoques, es en la Escuela de Alejandría cuando por primera vez se fundamenta el estudio de la Anatomía sobre una base racional; la disección de los cadáveres, actividad hasta entonces vetada por la ignorancia y la superstición, así en el Museo, la primer universidad que existió en el mundo, Herófilo y Erasistrato llevan a cabo algo completamente nuevo en la enseñanza escolarizada de la Medicina, el estudio de la Anatomía Humana como un elemento parte de la realidad objetiva, utilizando como herramienta la disección (Montemayor, 1997).

La enseñanza de la Medicina se ve enriquecida con el conocimiento de la anatomía del cuerpo humano y así desde el Museo se da el primer paso en la transformación de la medicina, de una actividad con carácter artesanal hacia una actividad con objetividad científica.

Tal fue la fuerza de la anatomía alejandrina que Galeno, uno de sus alumnos, marcó los siguientes 15 siglos de estudios anatómicos. 
Los primeros años de la historia del cristianismo se caracterizaron por el desprecio al cuerpo, la desvalorización como materia de estudio, por lo que en las Escuelas de Medicina dejaron de practicarse las disecciones. El estudio de la anatomía mediante prácticas de disección que caracterizaron a la escuela alejandrina necesitó esperar la llegada de Renacimiento.

Con el Renacimiento la mirada sobre el cuerpo humano se transformó, de materia despreciable a un objeto de interés y estudio científico, el cuerpo es revalorado y se inicia la llamada revolución anatómica.

Las universidades reforman sus cursos de anatomía, la Universidad de Padua durante el siglo XVI atrajo a profesores de medicina de gran prestigio, ofreciendo facilidades para la práctica de disecciones en cadáver, un joven estudiante belga es atraído por los aires de renovación académica, Andreas Vesalius. Este estudiante de 22 años será el responsable de marcar un parteaguas en la enseñanza de la Anatomía.

La Anatomía moderna se inicia con la publicación de su obra "De humani corporis fabrica libri septem" en 1542, enseñando a los médicos que el cuerpo humano es el mejor de los libros para aprender anatomía (Montemayor, 1997).

El Magisterio de Vesalio rompió con el sistema didáctico medieval, él enseñaba junto al cadáver, disecando y mostrando por sí mismo la región que la explicación refería, después dibujaba ante sus oyentes lo que no era fácil de ver.

Así la anatomía descriptiva se abre camino en las universidades europeas de vanguardia, como en Padua y en París, utilizando el método revolucionario de Vesalio el cual combinaba cadáver, maestro, alumnos, libros, dibujos para ofrecer una mejor comprensión del cuerpo humano.

La Anatomía invade las escuelas de arte, nuevos artistas plásticos encuentran en ella el fundamento arquitectónico para mostrar desde la mirada artística este cuerpo recién descubierto.

Durante los siglos XVI y XVII, los siglos de oro de la Anatomía, el cuerpo humano habría de ser explorado, dibujado, disecado por entero.

La construcción de anfiteatros para la práctica de la disección surge durante el siglo XVII, en ese tiempo la enseñanza de la anatomía era totalmente práctica, y el maestro era quien mostraba las estructuras anatómicas, en lugar de leer desde su cátedra los libros de Galeno y Avicena (Barquín).

El estudio de la anatomía mediante la disección en humanos permitió que la medicina recibiera un gran impulso, desarrollando nuevas asignaturas que se han convertido en ciencias como Fisiología, Cirugía, Patología entre otras. Hacia el siglo XIX se inicia un nuevo viaje de exploración corporal fuera del anfiteatro, en los laboratorios y desde el microscopio, para mostrar ahora las estructuras anatómicas celulares.

A finales del siglo XX la computadora portátil invade los hogares y las escuelas, entonces la disección es llevada a la "realidad virtual" ofreciendo así oportunidades mayores para recrear al cuerpo, lo cual termina por ser de más fácil manejo y más económico que la preparación y mantenimiento de los cadáveres, entonces se propone abandonar las tradicionales prácticas de disección por sesiones frente a los monitores de las computadoras.

En los albores de este nuevo siglo la observación y manipulación del cadáver en la enseñanza de la Anatomía son aún los métodos por excelencia utilizados por los docentes (Babinsaki \& Segrott 2003).

En la mayoría de las Escuelas y Facultades de Medicina de plan tradicional en la República Mexicana actualmente la práctica de disección se encuentra integrada a la asignatura de Anatomía Humana y se ubica en el primer año de la licenciatura (Granados).

La falta de docentes calificados para impartir la práctica de disección, así como el alto costo del material y los recursos necesarios preparar, manejar y conservar los cadáveres ha obligado a algunas Facultades y Escuelas de Medicina a ofrecer a cambio prácticas más económicas como los programas de software sobre el cuerpo humano y modelos anatómicos elaborados en materiales plásticos. (Guiraldes y Odó, 1993; Bravo \& Inzunza 1995, Inzunza \& Bravo 1999).

Para un profesor de Anatomía la importancia de la práctica de disección puede estar a debate, pero la mayoría de quienes imparten esta asignatura en las curriculas tradicionales estarán de acuerdo de su trascendencia educativa en la formación médica.

Pero ¿qué opinan los estudiantes de medicina que cursan la práctica de disección?, ¿qué significa para ellos el contar con ese recurso educativo?

\section{MATERIAL Y MÉTODO}

Se trabajó con tres poblaciones de alumnos: dos grupos de 30 alumnos de primer año de la Facultad de Medicina de la Universidad Nacional Autónoma de México, de los ciclos escolares 2001-2002 y 2002-2003 y un grupo de 50 
alumnos graduados de la misma escuela pertenecientes a varias generaciones(de 1994 a 1998).

Se elaboró un cuestionario de respuesta abierta y ensayo breve para explorar la opinión que los estudiantes tienen sobre la práctica de la disección, el cual se aplicó a 30 alumnos, guiados por las respuestas obtenidas se desarrollo un instrumento el cual se aplicó a los alumnos de primer año en dos momentos, una semana después de iniciar las prácticas de disección y durante la última semana de actividad académica del ciclo escolar correspondiente, la aplicación del cuestionario a alumnos graduados se realizó durante el mes de enero del 2004.

\section{Encuesta aplicada}

Grupo

Contesta las siguientes preguntas

1. ¿Cuándo ingresaste a la licenciatura en medicina sabías que durante el primer año tendrías prácticas de disección?

a) Sí b) No

2. $i$ Recuerdas que fue lo que sentiste y pensaste la primera vez que te enfrentaste a un cadáver para realizar la disección?

a) No sentí nada en especial

b) Malestar

c) Curiosidad

d) Miedo

e) Repulsión

f) Interés

g)

3. ¿Cómo te sientes ahora cuando realizas disecciones?

a) No siento nada en especial

b) Malestar

c) Curiosidad

d) Miedo

e) Repulsión

f) Interés

g)

4. ¿Tienes idea clara de cómo estas prácticas de disección se integran al perfil del médico egresado de esta Facultad?

a) Sí b) No

5.¿Para qué crees que te va a servir la práctica de disección en tu formación como médico?

a) Integrar la teoría con la realidad

b) Aprender a trabajar en equipo

c) Para la Cirugía

d) Aplicarla en la clínica

e) Ubicar topográficamente los órganos

f) Identificar proyección anatómica

g) Confirmar lo que se aprende en los libros

\section{RESULTADOS}

Los resultados nos indican que los alumnos que ingresan a la Licenciatura en Medicina en la Facultad de Medicina UNAM saben de antemano que durante el primer año de su formación como médicos realizarán prácticas de disección.

Su primer contacto con el cadáver provoca un sentimiento de curiosidad, el cual es reemplazado por interés (Figs. $1,2$ y 3$)$.

Si bien los alumnos de primer año declararon en un alto porcentaje tener una idea muy clara sobre la forma en que la disección se integrará al perfil profesional del médico egresado de la institución (100\% y 72\%), esta condición no es igual en la población de alumnos graduados, en donde el porcentaje disminuye (49\%).

Figs. 1a y $1 b$.

¿ Recuerdas que fue lo que sentiste y pensaste la primera vez que te enfrentaste a un cadáver para realizar la disección? Graduados

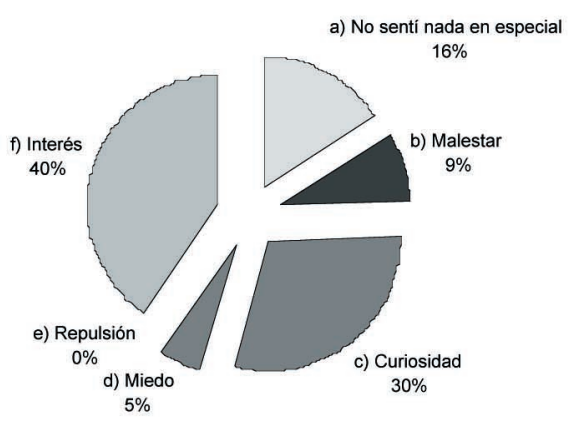

a

¿Cómo te sientes ahora cuando realizas disecciones? Graduados

b

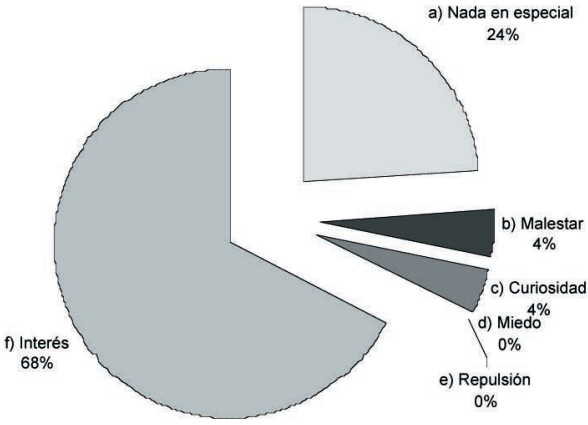


Figs. 2a y $2 b$.

¿ Recuerdas que fue lo que sentiste y pensaste la primera vez que te ¿Cómo te sientes ahora cuando realizas disecciones? enfrentaste a un cadáver para realizar la disección?

Generación 2002
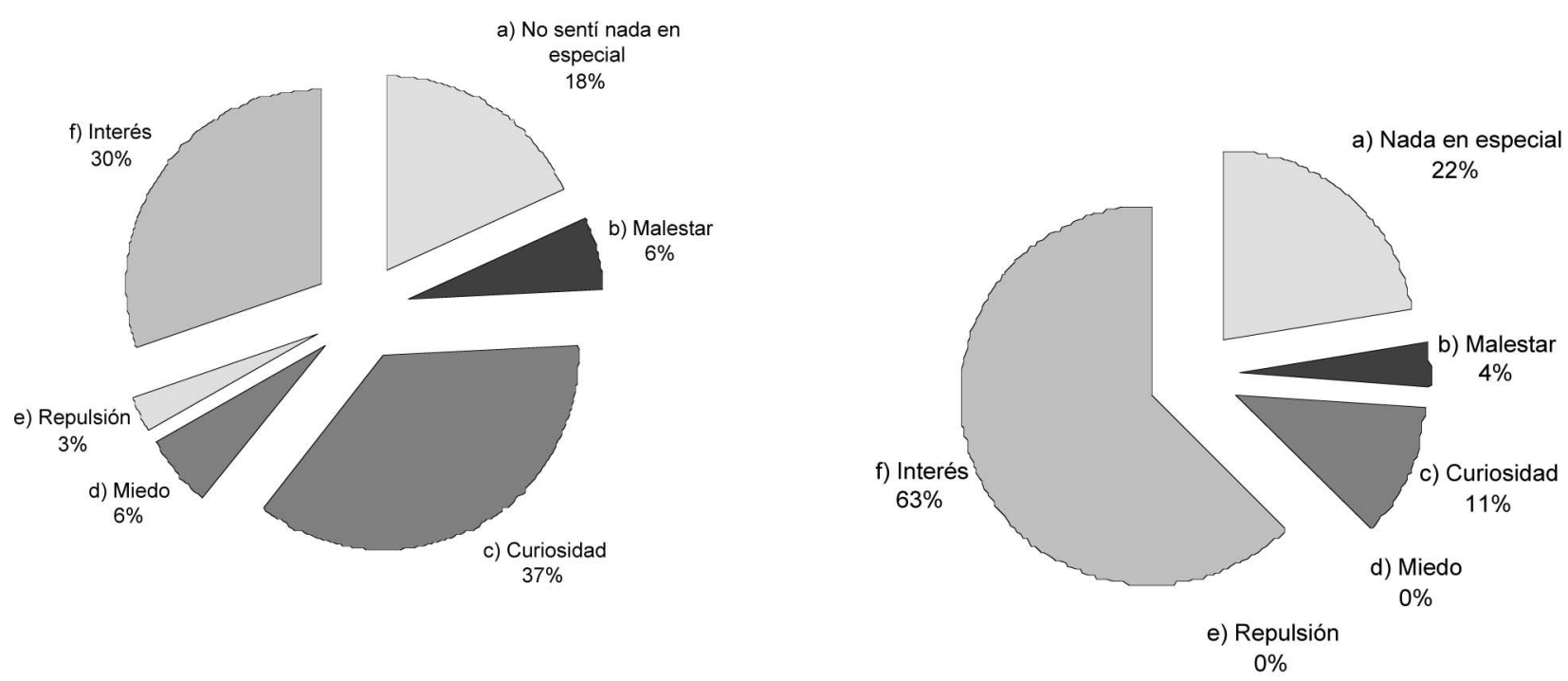

¿ Recuerdas que fue lo que sentiste y pensaste la primera vez que te enfrentaste a un cadáver para realizar la disección? Generación 2003

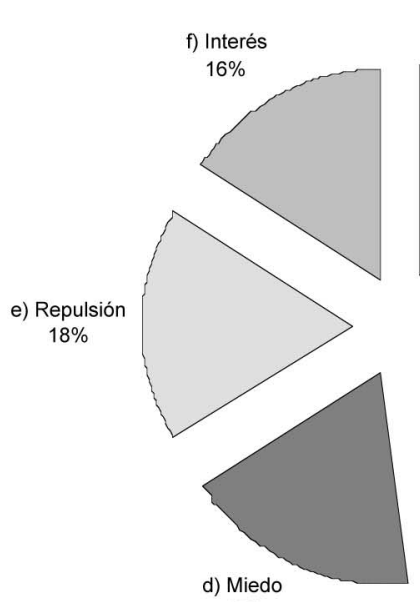

$18 \%$

Figs. 3a y 3b.

a) No sentí nada en especial

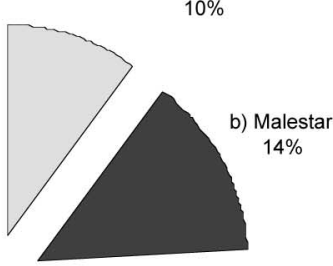

¿Cómo te sientes ahora cuando realizas disecciones? Generación 2003
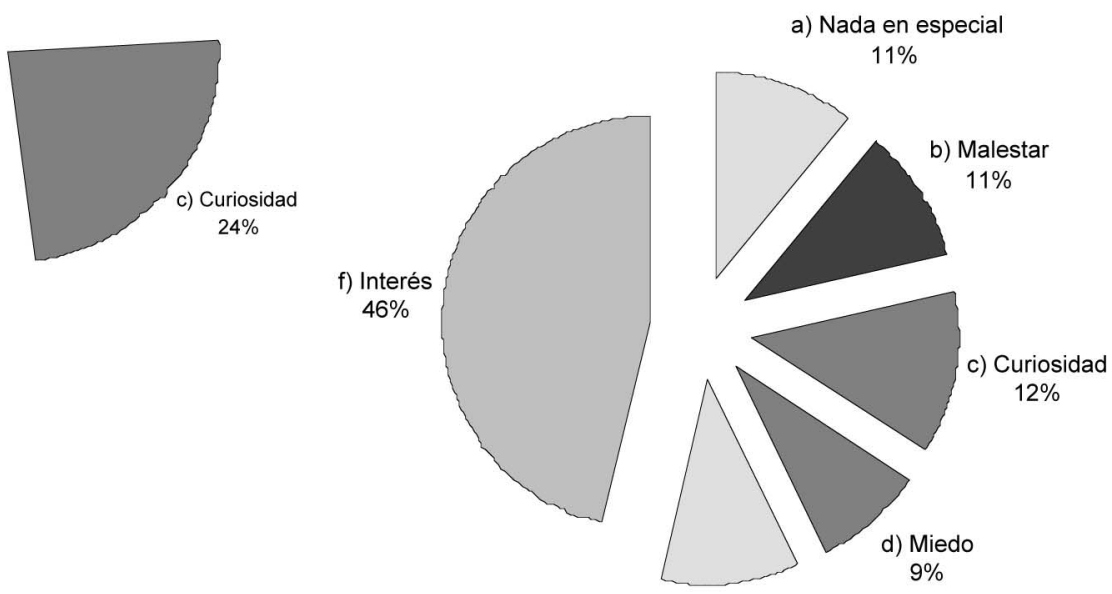

e) Repulsión $11 \%$ 
Las respuestas a la pregunta, ¿para qué crees que te va a servir la práctica de disección en tu formación como médico? se presentan en la Fig. 4.

Fig. 4. ¿Para qué te va a servir la práctica de disección en tu formación como médico?

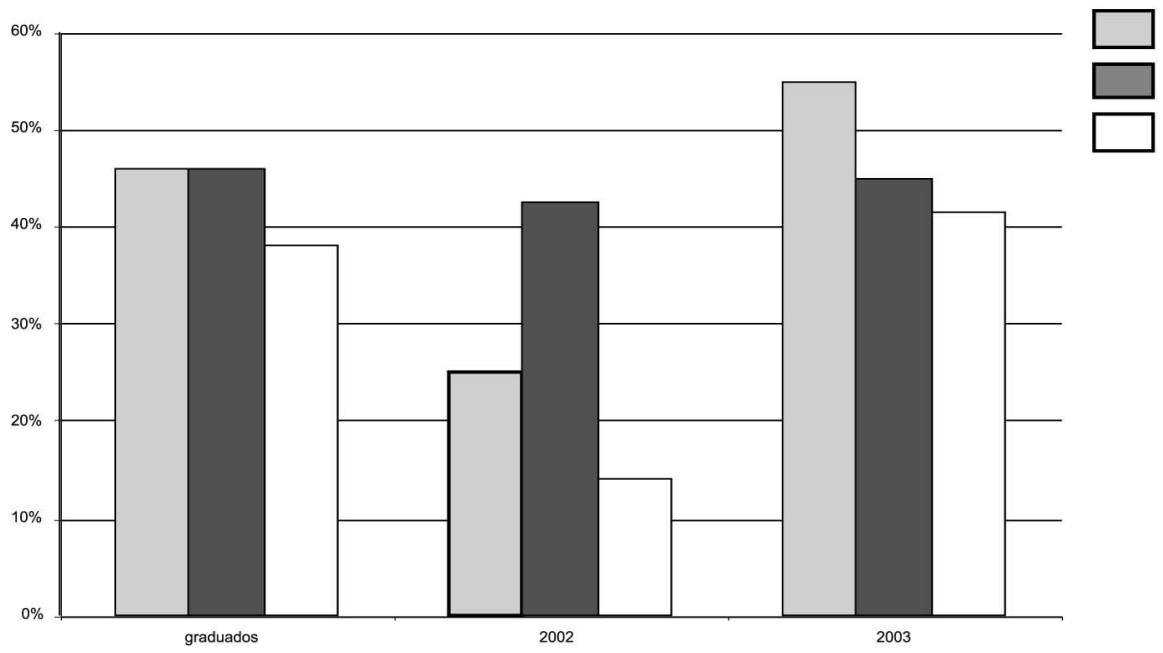

Integrar la teoría con la práctica

Ubicar topográficamente a los órganos

Aplicar a la clínica

\section{DISCUSIÓN}

El análisis de los resultados nos lleva a pensar que a pesar de las grandes transformaciones en la enseñanza escolarizada de la Anatomía y de los cambios en la práctica médica, aún hoy en el siglo XXI ante los alumnos que ingresan a la Licenciatura en Medicina la imagen más familiar de lo que les espera durante ese primer año de formación sigue siendo la práctica de la disección.

Para muchos de los alumnos el trabajo práctico de disección representa el primer contacto con la evidencia física de la muerte, lo cual sin lugar a dudas les genera un sentimiento de curiosidad, el cual se transforma en interés conforme se avanza en el estudio de la Anatomía. Estos resultados coinciden con lo reportado en otras investigaciones (Babinski \& Sgrott ) donde las reacciones de los alumnos ante el cadáver durante el trabajo práctico de la anatomía se identificó como de curiosidad ante el primer contacto en el $40.8 \%$.

Nuestro trabajo muestra como los estudiantes transforman esa incipiente curiosidad en interés por conocer y comprender las estructuras anatómicas.

Estudios similares realizados en otras poblaciones escolares ha señalado que el interés que los alumnos muestran ante los programas computacionales no supera el que manifiestan éstos por las prácticas de disección, los alumnos reconocen que el trabajo práctico de la disección es un método que contribuye de manera eficiente en la comprensión de las relaciones anatómicas en el espacio (Babinski \& Sgrott).
Alumnos de medicina expuestos a diferentes recursos didácticos; software educativo, esquemas anatómicos tratados como mapas sensibles, modelos plastinados y prácticas de disección, presentan un mayor rendimiento en el reconocimiento de elementos anatómicos cuando realizan el trabajo práctico de la disección (Inzunza et al. 2003).

El análisis de las respuestas a la pregunta, ¿para qué crees que te va a servir la práctica de disección en tu formación como médico? nos lleva a pensar que los alumnos reconocen a la disección como un importante antecedente para el ejercicio médico, ya que les permite acercarlos a la realidad del cuerpo humano, reconocer su topografía y aplicarla a la clínica ya como proyecciones anatómicas, o como coordenadas para el ejercicio de la cirugía.

La diferencia en las respuestas sobre la relación entre la práctica de disección y el perfil de egresado sin duda se debe a madurez de los estudiantes y al tiempo transcurrido en su formación médica, no podemos evitar pensar que la falta de experiencia de los alumnos que inician la licenciatura les lleva a concebir la profesión médica de manera diferente a lo que un alumno graduado y en contacto con la práctica médica puede tener como referencia.

La disección sigue siendo una experiencia de aprendizaje reconocida y apreciada por los alumnos, los comentarios y críticas recurrentes de los alumnos sobre la asignatura de Anatomía suelen dirigirse hacia la necesidad de privilegiar la práctica de disecciones (Jones, 1997; Barrovechio et al., 1998; Moore, 1998; Inzunza et al.). 
El trabajo práctico de la disección enfrenta a los alumnos a retos cognitivos en donde deben reconocer y relacionar los elementos anatómicos en arreglos espaciales tridimensionales, destacando posición y relaciones con estructuras adyacentes, rompiendo con el acostumbrado ejercicio de preguntas y respuestas que se van alternando, común en nuestras aulas (Inzunza et al.).

La disección permite a los alumnos acercarse al objeto de estudio, el cuerpo humano, en un contexto real, en donde se resaltan las pequeñas variaciones anatómicas, origen y trayectos que en un sujeto vivo suelen presentarse y que durante los inicios de la práctica profesional pueden desorientarlos y confundirlos.
El alumno al realizar la disección se va aproximando a la realidad del cuerpo humano plano a plano, visualizando el territorio anatómico, identificando las estructuras presentes en cada uno de los planos que descubre durante este viaje de exploración en el complejo arreglo anatómico.

Durante la larga historia académica de la enseñanza de la Anatomía Humana los docentes se han apoyado en diversas estrategias metodológicas, permaneciendo como constante una, la más antigua de todas, que ha pesar de todo este tiempo transcurrido no ha dejado de ser vigente, la práctica de la disección.

MONTEMAYOR, F. B. G. What de dissection meaning for medical students. Int. J. Morphol., 24(4):575-580, 2006.

SUMMARY: Many centuries ago during the III century B.C. at the Museum of Alexandria, begun the practice of the anatomy dissection. In almost 23 centuries this practice was transforming from a rational exercise to he virtual reality, pass by the prohibition and the tradition lecture imposed by galenic anatomist.

What think about dissection the medical students of the XXI Century, whom during their first year of the medical school to be comforting every day with this practice? We asked that to the students of the Medical School at National Autonomous University of Mexico.

The results of that work talk us about the actuality of this ancient at the same time modern learning strategy who allows approach to the physical and spatial reality of the human body.

KEY WORDS: Human Anatomy: Dissection; Medical education; Teaching of anatomy.

\section{REFERENCIAS BIBLIOGRÁFICAS}

Babinski, M. A.; Sgrott. E. A.; Luz, H. P.; Brasil, F. B.; Chagas, M. A. \& Abidu-Figueiredo, M. La relación de los estudiantes con el cadáver en el estudio práctico de la anatomía: La reacción e influencia en el aprendizaje. Int. J. Morphol., 21(2):137-42, 2003.

Barquín C. Historia de la Medicina. México, Méndez Editores, 1995.

Barrovecchio, J. C.; Pérez, B. \& Bella de Paz, L. Sugerencias acerca del proceso de enseñanza-aprendizaje en Anatomía Humana. Rev. Chil. Anat., 16(2):219-24, 1998.

Collipal, L. E. Conceptualización a través de redes semánticas naturales de los módulos de autoaprendizaje en Anatomía Humana. Rev. Chil. Anat., 20(1):63-7, 2002.

Guiraldes, H.; Oddó, H.; Mena, B.; Velasco, N. \& Paulos, J. Enseñanza de la Anatomía humana: Experiencias y desafíos en una escuela de Medicina. Rev. Chil. Anat., 19(2), 2001.

Inzunza, O. \& Bravo, H. Impacto de dos programas computacionales de Anatomía Humana en el rendimiento del conocimiento práctico de los alumnos. Rev. Chil. Anat., 17(2):205-9, 1999.

Inzunza, O.; D’Acuña, E. \& Bravo H, Evaluación práctica de anatomía, rendimiento de los alumnos de primer año de medicina ante distintas formas de preguntar. Int. J. Morphol., 21(2):131-6, 2003.
Jones, D. G. Reassessing the importance of disecction: a critique and elaboration. Clin. Anat., 10:123-7, 1997.

Montemayor, R. Andrea Vesalius. Rev. Vesalius Dep. Anatomía, Fac. Med. UANL, 1994.

Montemayor, G. La Anatomía Humana y el Arte. Rev Vesalius Dep. Anatomía, Fac. Med. UANL, 1997.

Montemayor, G. Los paradigmas en la enseñanza de la anatomía humana. Rev. Fac. Med. UNAM., 42 (1), 1999.

Moore, N. A. To dissect or not dissect. Anat. Rec., 253:8-9, 1998.

Rojas, M.; Montiel, J.; Ondarza,A., Rodríguez, H. Estudio comparado entre métodos de enseñanza tradicional y computacional en histología humana. Rev. Anat., 17(1):81-5, 1999.

Dirección para correspondencia:

Dra. Beatriz Georgina Montemayor Flores

Departamento de Anatomía, Facultad de Medicina

Universidad Nacional Autónoma de México

M'éxico - DF

MÉXICO

Email:betyg@servidor.unam.mx

Recibido : 23-11-2005

Aceptado: 25-08-2006 